\title{
Correspondence
}

\section{A tribute to Douglas Gairdner}

\section{Sir,}

I should like to state the feelings of Portuguese paediatricians about Dr Douglas Gairdner, who came several times to Portugal, invited by the Portuguese Academy of Paediatrics. Every time Douglas made an immediate integration. He never gave us the impression of a foreign scientist giving lectures. He was always interested to hear about our problems and his advice was realistic and full of experience and common sense.

Travelling around Portugal he was not a tourist. $\mathrm{He}$ has the natural capacity of mixing with people and participating in local life. Alone by himself he enjoyed the happy disorder of 3rd class in Iberic trains, where without understanding one single word of the conversation, he managed to start contacts and to communicate. He had the initiative to search for regional art, to visit popular restaurants, to try local food-with obvious pleasure - to hear fado with application, to bathe on our beaches, and to live every moment as if he were born here.

This human quality makes Douglas the best paediatric ambassador that ever came to Portugal.

$$
\begin{array}{r}
\text { J M Ramos De Almeida } \\
\text { President, } \\
\text { Sociedade Portuguesa de Pediatria, } \\
\text { Clinica Pediátrica Universitária, } \\
\text { Hospital de Santa Maria, } \\
\text { Lisbon, Portugal }
\end{array}
$$

\section{Medicines cause decayed teeth}

Sir,

As a dentist concerned in arranging provision of dental care for chronically ill children, I am worried about the effect of sugar-containing medicines on their teeth. One of the most important factors in the aetiology of dental decay is frequent ingestion of sugar. Short-term use of sugar-based paediatric medicines will cause minimal damage but prolonged use may cause serious dental disease. ${ }^{1}$ This is particularly unfortunate in chronically ill children in whom dental sepsis or the need to extract teeth may create a serious hazard to general health.

The long-term and most effective method for overcoming this problem would be for the pharmaceutical industry to substitute artificial sweeteners or other flavouring agents that do not cause decay. Every effort should be made to encourage the industry to act in this matter. In the meantime there are steps which paediatricians might be prepared to take which would reduce the incidence of medicine-induced dental decay:

(1) Whenever possible prescribe medicine to be taken at meal times rather than between meals or at bedtime.

(2) When it is essential that medicine be taken at bedtime, tooth brushing afterwards may help to reduce the extent of the damage. However, this is of limited benefit as the toothbrush bristles do not remove sugar-containing plaque from the inaccessible areas where decay develops. (3) Prescribe the drug in some other form (for example tablets) as soon as this is acceptable to the child. A list of preparations suitable for children, with and without sugar, is available from the Area Pharmaceutical Officer, West Sussex Area Health Authority, Courtlands, Parklands Avenue, Goring, Sussex BN12 4NQ.

I should like to make a plea that paediatricians consider this problem when prescribing for children. It is unfortunate that medicines used to treat one disease may be causing others to develop in different parts of the body, thus causing pain or even more serious consequences.

\section{Reference}

1 Roberts I F, Roberts G J. Relation between medicines sweetened with sucrose and dental disease. $B r$ Med J 1979; ii: $14-6$.

Pamela Hobson

Department of Child Dental Health, University Dental Hospital of Manchester, Bridgeford Street, Manchester M15 6FH

\section{Xanthines and necrotising enterocolitis}

Sir,

Xanthine derivatives have been shown to be useful in the management of neonatal apnoea. ${ }^{1}$ We report 3 cases of necrotising enterocolitis (NEC) in children receiving oral xanthines.

\section{Case 1}

A 920-g 28-week gestation boy, who had been previously well, developed apnoea on day 21 . The apnoeic attacks responded to oral theophylline $3 \mathrm{mg} / \mathrm{kg}$ 6-hourly which was continued until day 31 when NEC developed.

\section{Case 2}

A 960-g 27-week gestation girl had severe respiratory distress needing ventilatory support until day 17 . Intravenous aminophylline followed by oral theophylline were administered and NEC developed on day 30 . 